(C) 2018, The Authors. Published by FASS Inc. and Elsevier Inc. on behalf of the American Dairy Science Association ${ }^{\circledR}$.

This is an open access article under the CC BY-NC-ND license (http://creativecommons.org/licenses/by-nc-nd/4.0/).

\title{
Hot topic: Management of cull dairy cows-Consensus of an expert consultation in Canada
}

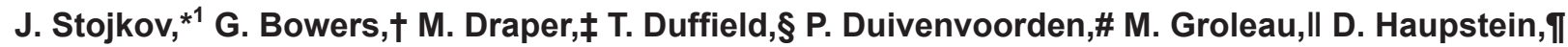

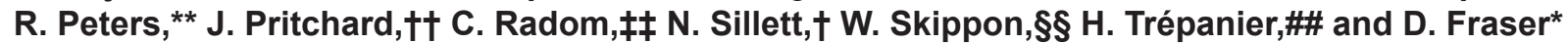 \\ *Animal Welfare Program, Faculty of Land and Food Systems, The University of British Columbia, 2357 Main Mall, Vancouver, BC V6T 1Z4, \\ Canada \\ †Dairy Farmers of Canada, 21 Florence Street, Ottawa, ON K2P 0W6, Canada \\ †Ontario Ministry of Agriculture, Food and Rural Affairs, 1 Stone Road West, Guelph, ON N1G 4Y2, Canada \\ $\S$ Ontario Veterinary College, University of Guelph, 50 Stone Road E., Guelph, ON N1G 2W1, Canada \\ \#Headline Holsteins Ltd., 191 Goose Arm Rd., Deer Lake, NL A8A 3H9, Canada \\ \|Canadian Food Inspection Agency, 59 Camelot Drive, Ottawa, ON K1A 0Y9, Canada \\ ISaskatchewan Milk Marketing Board, 444 McLeod Street, Regina, SK S4N 4Y1, Canada \\ **Steve's Livestock Transport Ltd., 214 Centre Ave., Blumenort, MB R0A 0C0, Canada \\ ††Ministry of Agriculture, 1767 Angus Campbell Road, Abbotsford, BC V3G 2M3, Canada \\ $\ddagger \ddagger$ Canadian Association of Bovine Veterinarians, 226E Wheeler Street, Saskatoon, SK S7P 0A9, Canada \\ §Saputo Inc., 6869 Métropolitain Est Montréal, QC H1P 1X8, Canada \\ \#\#Ministère de l'Agriculture, des Pêcheries et de l'Alimentation, 200 chemin Sainte-Foy, Ville de Québec, QC G1R 4X6, Canada
}

\section{ABSTRACT}

Many cull dairy cows enter the marketing system and travel to widely dispersed and specialized slaughter plants, and they may experience multiple handling events (e.g., loading, unloading, mixing), change of ownership among dealers, and feed and water deprivation during transport and at livestock markets. The objectives of this study were to describe the diverse management of cull dairy cows in Canada and establish consensus on ways to achieve improvements. A 2-day expert consultation meeting was convened, involving farmers, veterinarians, regulators, and experts in animal transport, livestock auction, and slaughter. The 15 participants, recruited from across Canada, discussed regional management practices for cull cattle, related risk factors, animal welfare problems, and recommendations. An audio recording of the meeting was used to extract descriptive data on cull cattle management and identify points of agreement. Eight consensus points were reached: (1) to assemble information on travel times and delays from farm to slaughter; (2) to increase awareness among producers and herd veterinarians of potential travel distances and delays; (3) to promote pro-active culling; (4) to improve the ability of personnel to assess animal condition before loading; (5) to identify local options for slaughter of cull dairy cows; (6) to investigate different management options such as emergency slaughter and mobile slaughter; (7) to ensure that all farms and auctions have, or can access,

Received April 12, 2018.

Accepted August 27, 2018.

${ }^{1}$ Corresponding author: stojkov@mail.ubc.ca personnel trained and equipped for euthanasia; and (8) to promote cooperation among enforcement agencies and wider adoption of beneficial regulatory options. Key words: animal welfare, culling decisions, policy, transportation

\section{Hot Topic}

The management of cull dairy cows (i.e., cows removed from the milking herd and sent for slaughter or salvage) is a significant animal welfare challenge that has received little systematic attention in policy and research. Currently, about 28 to $33 \%$ and 30 to $35 \%$ of dairy cows are removed from dairy herds each year in Canada (CDIC, 2017) and the United States (Pinedo et al., 2010), respectively. Some of these are healthy animals that are culled because of low production or failure to breed or simply to rejuvenate the milking herd, but many are culled because of compromised health. For example, in a survey of cull cows arriving at auction yards in the United States, Ahola et al. (2011a) reported that $18 \%$ of cull dairy cows were lame (lameness score $\geq 3$ on a 5 -point scoring system), mastitis was diagnosed in $3 \%$, and $13.3 \%$ had a BCS of $<2$. In a similar study at slaughter plants in the United States, $18 \%$ of cull dairy cows had lameness score $\geq 3,9 \%$ had mastitis, and $22 \%$ had a BCS of $<2$ (Nicholson et al., 2013). Collectively, these studies confirm that many cull dairy cows in North America arrive at auctions and slaughter plants with compromised health that could have developed at the farm of origin, during transport, or while in the marketing system.

Cull dairy cows present a range of challenges. Because cull cows are a somewhat specialized segment of 
the beef market, many slaughter plants do not accept them. Hence, animals with compromised health may be transported significant distances. Most cull dairy cows are marketed through auction yards (64\%; Glaze and Chahine, 2009), and thus experience additional handling and transport. Moreover, as cull dairy cows are often shipped from farms in small numbers, delays and mixing of animals may occur before transporters have assembled a load ready for slaughter. The problems may be especially significant in large countries such as Canada and the United States, where dairy production is spread over large geographic areas and slaughter plants are scarce in some locations. Despite these challenges, management of cull dairy cows has received remarkably little research.

Expert consultation was chosen as the method for this study because it is often used as an initial research method for complex problems, especially where there may be significant geographic variation (e.g., Fraser et al., 2009). The goals were to describe the extent and diversity of cull dairy cow management using Canada as a case study, to identify challenges and possible solutions, to identify additional needs for research, and to develop consensus recommendations on actions and policy.

Experts with 8 types of involvement in management of cull dairy cows were identified: dairy producers, veterinary practitioners, federal regulators, provincial regulators, researchers, and individuals with extensive experience in livestock transportation, auction, and slaughter. Experts were drawn from the 5 main regions of Canada with significant dairy production: British Columbia, the Prairie Provinces, Ontario, Quebec, and Atlantic Canada. Participants were identified and recruited using "key informants" (Hammersley and Atkinson, 2007), including members of the National Farmed Animal Health and Welfare Council (NFAHWC, Bluevale, ON, Canada), Dairy Farmers of Canada (DFC, Ottawa, ON, Canada), Canadian Food Inspection Agency (CFIA, Ottawa, ON, Canada), provincial and federal government officials, and the University of British Columbia (UBC) Animal Welfare Program. Of the 17 invited participants, 15 attended the consultation meeting and 2 provided their contributions and comments after the meeting while a consensus statement (described below) was being developed.

Experts met on March 23-24, 2016, in Ottawa, and worked through a planned agenda that covered (1) the management and movement patterns of cull dairy cows in different regions, (2) potential animal welfare problems, (3) tools available for dealing with compromised cull dairy cows, (4) risk factors related to current management practices, and (5) recommendations for stakeholders. On each topic, the experts reported personal observations, shared their experience, and provided their opinions related to their region and sector of involvement. The meeting was chaired by D. Fraser and coordinated by J. Stojkov and N. Sillett; all attendees provided input in the discussion. The meeting was supported by the NFAHWC and approved by the UBC Behavioral Research Ethics Board.

Written notes were taken during the meeting and the entire meeting was audio-recorded. Additional details from the discussion were later added to the written notes by listening to the audio recording. Content analysis (see Coffey and Atkinson, 1996) was used to identify certain themes that occurred frequently in the written notes. Themes that were widely supported by observations and reports from the experts were identified by 2 of the authors and became the basis for defining the 8 points of agreement. These were summarized and sent to all participants as a draft "consensus statement" for further refinements and corrections. This process was repeated 2 additional times until no further changes (except editorial improvements) were proposed. The discussion centered on 8 main themes, and a consensus recommendation emerged for each one.

\section{(1) The Need for Information and Analysis}

Experts noted that the management of cull dairy cows varies widely depending on the location. Where the option exists, some producers ship cows directly to a nearby slaughter plant and the animals are slaughtered promptly. More often, cows are sent to a livestock auction from where they may be shipped to a plant, possibly some distance away, or bought by dealers who may resell them one or more times in a process that may involve repeated handling and lengthy transportation. As examples from Canada, some cull dairy cows from Newfoundland are slaughtered in Ontario (a distance of $\sim 2,500 \mathrm{~km}$ ); some cull cows from Quebec have been identified in British Columbia $(\sim 4,500 \mathrm{~km})$; and cows from several provinces are commonly slaughtered in the United States. Experts considered that the time from farm to slaughter could be as much as 7 to $10 \mathrm{~d}$ in some cases. Reasons for long delays and distances include lack of local slaughter plants willing to accept cull cows, temporary lack of slaughter capacity at busy times, the closure of one plant that formerly processed cull dairy cows from a large area, and the need for cattle dealers to assemble a full load before driving to a distant slaughter plant.

The consensus of the meeting was that research/ investigation is needed, using available sources of information, to better characterize cull cow management and movement from farm to slaughter and the factors that lead to long delays. 


\section{(2) The Need for Awareness}

In many cases, producers and herd veterinarians are not aware of the extent of the transport and delay that may occur when they make culling decisions. In particular, some may assume that cattle sent to a livestock auction will have relatively little delay until slaughter, whereas the reality may be very different.

The consensus was that communication is needed to make producers and herd veterinarians aware of the potential for long travel distances and delays so that this information can be taken into account when culling decisions are made.

\section{(3) Pro-Active Culling}

In many cases, pro-active culling can prevent cattle from developing significant health and welfare problems (e.g., lameness, serious loss of body condition) that reduce both animal welfare and the commercial value of the animal. Pro-active culling might be promoted by providing training materials to both producers and herd veterinarians, by including the herd veterinarian in culling decisions, and by promoting greater recognition among dairy producers that they are producing a valuable meat product and hence the potential advantage of shipping cattle before they lose their value for slaughter.

The consensus was that training materials on the benefits of early culling decisions should be developed and provided to producers and veterinarians; that early culling criteria should be a part of every herd health program; and that producers should consider including the herd veterinarian in culling decisions, so that proactive culling of noncompromised animals becomes the norm.

\section{(4) Animal Condition}

Experts noted that cows culled for health reasons vary widely in their condition, with different degrees of lameness, body condition, mastitis, metritis, displaced abomasum, and pneumonia. The condition of the animal and the potential delays to slaughter need to be considered when culling decisions are made. Compromised cows can deteriorate quickly when transported. As examples, displaced abomasum can severely affect animal welfare if several days elapse before slaughter, and cows may develop mastitis if they are not dried off before long-duration handling and transportation. Each animal's fitness for the longest potential journey should be assessed before loading.

The consensus was (1) that a fitness-for-transport decision tree, which includes both the animal's con- dition and the potential delay to slaughter, be made widely available; (2) that the herd veterinarian play an active role in guiding producers on determining fitness for transport; and (3) that personnel involved in transport and auctions be trained to recognize and handle compromised cattle, including awareness of appropriate criteria for deciding to load animals for the potential journey.

\section{(5) Opportunities for Local Slaughter}

Some long distances and lengthy delays occur because of a lack of opportunities for local slaughter, either because plants are not available or will not accept cull dairy cows.

The consensus was that efforts must be made to identify more local options for the slaughter of cull dairy cows, perhaps through agreements between producer organizations and slaughter plants, to make short transport distances and timely slaughter the norm for cull cows, especially those at high risk of animal welfare problems.

\section{(6) Options for Management of Compromised Animals}

Experts reported that different jurisdictions have different management options for cull dairy cows:

- In Ontario, authorized veterinarians are empowered to use a "direct-to-slaughter" tag so that compromised animals received at an auction must proceed directly to a nearby slaughter plant and not go through the normal (potentially lengthy) marketing process.

- On-farm emergency slaughter is allowed in some provinces. In this case, the animal receives antemortem veterinary inspection on the farm, is then killed and bled on the farm, and is transported to a nearby slaughter plant for postmortem inspection before entering the food system.

- Mobile slaughter is permitted in some jurisdictions. This allows the entire slaughter process to occur without transporting the animal, and the animal (pending inspection) may then enter the food system.

The different options have potential advantages and disadvantages in terms of animal welfare, food safety, biosecurity, and economics.

The consensus was that the various options for cull cow management need to be investigated thoroughly so that they can be considered for more widespread adoption. 


\section{(7) Euthanasia}

Experts noted that on-farm euthanasia is the only acceptable option if an animal cannot be shipped and would suffer if kept alive for other options such as emergency slaughter. Producers need training in making decisions about euthanasia, plus either suitable training and tools to perform euthanasia or ready access to euthanasia services, including carcass disposal. Veterinarians need suitable training so that they can support humane on-farm practices.

The consensus was that all dairy farms and auctions should have the training and tools needed for prompt, effective euthanasia or access to euthanasia services, and that a euthanasia protocol should be part of every herd health program.

\section{(8) Enforcement}

Consistent enforcement of the relevant regulations could help to address animal welfare problems and create public confidence. In contrast, inconsistent enforcement could lead to animal welfare problems if it creates an incentive for compromised animals to be sent to locations where inspection is less frequent or less rigorous. Moreover, enforcement can be complicated if the animal changes ownership repeatedly between farm and slaughter so that different people are responsible for judging fitness for travel. At present, enforcement related to the management of cull dairy cows involves several agencies and is handled in somewhat different ways in different jurisdictions.

- The CFIA is responsible for enforcing federal animal transport regulations; CFIA staff are present at all federally inspected slaughter plants and periodically at auctions, assembly yards, and other locations to determine compliance.

- Provincial officials enforce various provincial regulations at slaughter plants and elsewhere depending on the jurisdiction. Inspection is periodic or complaint-based in some provinces, whereas Ontario requires that inspectors are present at auctions on any day when auction is conducted.

- In some provinces, Society for the Prevention of Cruelty to Animals (SPCA) inspectors enforce animal welfare/cruelty laws and may attend auction or assembly yards, typically on a complaint basis.

- In some provinces, provincial inspectors are authorized to monitor compliance with federal animal transport regulations to achieve more efficient inspection and sharing of information between federal and provincial authorities.
- In some provinces, producer organizations are formally involved in certain corrective actions, for example, by visiting producers who are found to have shipped compromised animals.

The consensus was that the different models of enforcement should be examined with a view to recommending the widespread and harmonized adoption of practices deemed best for the protection of animal welfare, and that enforcement authorities consider formal cooperation to facilitate sharing of information.

\section{General Discussion}

The welfare of cull dairy cows is a complex issue that depends on infrastructure (e.g., local slaughter options), on decisions made by producers and other actors, on economic factors such as the value of the carcass, and on regulatory environments and options, which vary among jurisdictions. Moreover, cull dairy cows are not a uniform group; for instance, a degree of handling and transport that is suitable for a healthy animal culled because of low milk production may be completely unsuitable for an animal that is very thin or lame. In the absence of comprehensive research on the issue, pooling knowledge from actors from all relevant sectors and with broad geographic experience provides an alternative form of understanding.

The difficulty of following the movement and condition of cull dairy cows once they leave the farm creates an information vacuum. One study indicated that, compared with feeders and fat cattle, cull cattle (beef and dairy) were more likely to be lame at loading and when arriving at auction markets (González et al., 2012). When transported $\geq 400 \mathrm{~km}$, cull cattle (compared with other categories of cattle) were more likely to become lame or nonambulatory or to die during the journey (González et al., 2012). Similarly, higher mortality rates in cull dairy cattle during transport were reported in European studies (Večerek et al., 2006; Malena et al., 2007). These findings indicate inadequate fitness for transport of some cull cows and negative effects of long distance transport on the condition of cull cattle.

Previous work in Canada and the United States has shown considerable carcass losses because of problems during transport and handling, and has emphasized the need to improve the management and handling of dairy cattle (Van Donkersgoed et al., 2001; Nicholson et al., 2013). For example, Canadian beef quality audits indicated losses of $\$ 190$ million and $\$ 274$ million annually because of quality unconformities in all classes of cattle in 1995-1996 and 1998-1999, respectively (Van Donkersgoed et al., 1997, 2001). Both bruising and low BCS were more often present in dairy cows than in beef 
animals (Van Donkersgoed et al., 2001). Moreover, conditions leading to entire carcass condemnation included emaciation, bruising, and mastitis, which are common among dairy cows (Van Donkersgoed et al., 1997). Similarly, audits at livestock markets and slaughter plants in the United States identified several quality defects, including emaciation, lameness, and bruising, that lowered the market value of cull dairy cows; this led to recommended actions to improve on-farm management, particularly timely culling decisions (Ahola et al., 2011a,b; Nicholson et al., 2013).

A variety of insights arose from this exercise. These include the wide range of transport distances and times that cull dairy cows experience, some of the factors that influence delay and handling, and the variety of regulatory arrangements and options. In addition, the consultation gave rise to numerous recommendations for action by producers, producer organizations, veterinarians, regulators, and other players. Recommended areas for research include better documentation of transport distances and times and the advantages and disadvantages of different options such as direct-toslaughter and emergency slaughter. Such research could guide industry policy, actions, and codes of practice, and inform revisions to the Transportation of Animals regulations (JLW, 2018), which currently do not make explicit provision for cull dairy cows.

\section{ACKNOWLEDGMENTS}

We are grateful to Loblaw Companies Limited (Brampton, ON, Canada) for funding, and to the National Farmed Animal Health and Welfare Council (Bluevale, ON, Canada) for sponsoring the expert consultation. We thank Gordon Doonan (Ottawa, ON, Canada) and all experts who participated and contributed to this manuscript. General support for the UBC Animal Welfare Program is provided by the NSERC Industrial Research Chair Program with industry contributions from the Dairy Farmers of Canada (Ottawa, ON, Canada) and many others listed at http://awp landfood.ubc.ca/.

\section{REFERENCES}

Ahola, J. K., H. A. Foster, D. L. VanOverbeke, K. S. Jensen, R. L. Wilson, J. B. Glaze, T. E. Fife, C. W. Gray, S. A. Nash, R. R. Panting, and N. R. Rimbey. 2011a. Quality defects in market beef and dairy cows and bulls sold through livestock auction markets in the Western United States: II. Relative effects on selling price. J. Anim. Sci. 89:1484-1495.

Ahola, J. K., H. A. Foster, D. L. VanOverbeke, K. S. Jensen, R. L. Wilson, J. B. Glaze, T. E. Fife, C. W. Gray, S. A. Nash, R. R. Panting, and N. R. Rimbey. 2011b. Survey of quality defects in market beef and dairy cows and bulls sold through livestock auction markets in the Western United States: I. Incidence rates. J. Anim Sci. 89:1474-1483.

CDIC. 2017. Breed Improvement and Genetic Evaluation. Culling and replacement rates in dairy herds in Canada. Canadian Dairy Informational Center (CDIC). Accessed Dec. 28, 2017. http://www .dairyinfo.gc.ca/index_e.php?s1 $=$ dff-fcil\&s $2=$ mrr-pcle\&s3 $=$ cr-tr.

Coffey, A., and P. Atkinson. 1996. Concepts and coding. Pages 26-53 in Making Sense of Qualitative Data: Complementary Research Strategies. Sage Publications Inc., Thousand Oaks, CA.

Fraser, D., R. M. Kharb, C. M. E. McCrindle, J. Mench, M. Paranhos de Costa, K. Promchan, A. Sundrum, P. Thornber, P. Whittington, and W. Song. 2009. Capacity building to implement good animal welfare practices: Report of the FAO Expert Meeting. Food and Agriculture Organization of the United Nations (FAO), Rome, Italy.

Glaze, J. B. Jr., and M. Chahine. 2009. Assessment of management and basic beef quality assurance practices on Idaho dairies. J. Dairy Sci. 92:1265-1271.

González, L. A., K. S. Schwartzkopf-Genswein, M. Bryan, R. Silasi, and F. Brown. 2012. Relationships between transport conditions and welfare outcomes during commercial long haul transport of cattle in North America. J. Anim. Sci. 90:3640-3651.

Hammersley, M., and P. Atkinson. 2007. Oral accounts and the role of interviewing. Pages 97-120 in Ethnography: Principles in Practice. 3rd ed. Routledge, London, UK.

JLW. 2018. Health of Animals Regulations, Part XII-Transportation of Animals. Consolidated Regulations of Canada. Justice Laws Website (JLW). Accessed Sep. 3, 2018. http://laws-lois.justice.gc .ca/PDF/C.R.C.,_c._296.pdf

Malena, M., E. Voslářová, A. Kozák, P. Bělobrádek, I. Bedáňová, L. Steinhauser, and V. Večerek. 2007. Comparison of mortality rates in different categories of pigs and cattle during transport for slaughter. Acta Vet. Brno 76:109-116.

Nicholson, J. D. W., K. L. Nicholson, L. L. Frenzel, R. J. Maddock, R. J. Delmore, T. E. Lawrence, W. R. Henning, T. D. Pringle, D. D. Johnson, J. C. Paschal, R. J. Gill, J. J. Cleere, B. B. Carpenter, R. V. Machen, J. P. Banta, D. S. Hale, D. B. Griffin, and J. W. Savell. 2013. Survey of transportation procedures, management practices, and health assessment related to quality, quantity, and value for market beef and dairy cows and bulls. J. Anim. Sci. 91:5026-5036.

Pinedo, P. J., A. De Vries, and D. W. Webb. 2010. Dynamics of culling risk with disposal codes reported by Dairy Herd Improvement dairy herds. J. Dairy Sci. 93:2250-2261.

Van Donkersgoed, J., G. Jewison, S. Bygrove, K. Gillis, D. Malchow, and G. McLeod. 2001. Canadian beef quality audit 1998-99. Can. Vet. J. 42:121-126

Van Donkersgoed, J., G. Jewison, M. Mann, B. Cherry, B. Altwasser, R. Lower, K. Wiggins, R. Dejonge, B. Thorlakson, E. Moss, C. Mills, H. Grogan, J. Van Donkersgoed, G. Jewison, M. Mann, B. Cherry, B. Altwasser, R. Lower, K. Wiggins, R. Dejonge, B. Thorlakson, E. Moss, C. Mills, and H. Grogan. 1997. Canadian beef quality audit. Can. Vet. J. 38:217-225.

Večerek, V., M. Malena Jr., M. Malena, E. Voslářová, and I. Bedáňová. 2006. Mortality in dairy cows transported to slaughter as affected by travel distance and seasonality. Acta Vet. Brno 75:449-454. 